\title{
Validation of the Multidimensional Fatigue Inventory with Coronary Artery Disease Patients
}

\author{
Julija Gecaite-Stonciene * $\mathbb{C}^{\circ}$, Adomas Bunevicius ${ }^{\circledR}$, Julius Burkauskas ${ }^{\circledR}$, Julija Brozaitiene, \\ Julius Neverauskas, Narseta Mickuviene and Nijole Kazukauskiene ${ }^{\circledR}$ \\ Laboratory of Behavioral Medicine, Neuroscience Institute, Lithuanian University of Health Sciences, \\ 2100 Palanga, Lithuania; adomas.bunevicius@lsmuni.lt (A.B.); julius.burkauskas@lsmuni.lt (J.B.); \\ julijabrozaitiene@gmail.com (J.B.); julius.neverauskas@lsmuni.lt (J.N.); narseta.mickuviene@lsmuni.lt (N.M.); \\ nijole.kazukauskiene@lsmuni.lt (N.K.) \\ * Correspondence: julija.gecaite@lsmuni.lt; Tel.: +370-460-30012
}

Received: 24 September 2020; Accepted: 27 October 2020; Published: 30 October 2020

\begin{abstract}
Background: Fatigue is a common distressing symptom in patients with coronary artery disease (CAD). The Multidimensional Fatigue Inventory (MFI) is used for measuring fatigue in various clinical settings. Nevertheless, its multidimensional structure has not been consistent across studies. Thus, we aimed to psychometrically evaluate the MFI in patients with CAD. Methods: In sum, 1162 CAD patients completed questionnaires assessing their subjective fatigue level (MFI-20), mental distress symptoms (HADS, STAI), and health-related quality of life (SF-36). Participants also completed exercise capacity (EC) testing. Results: Confirmatory factor analysis of the four-factor model, showed acceptable fit $(\mathrm{CFI}=0.905 ; \mathrm{GFI}=0.895 ; \mathrm{NFI}=0.893$, RMSEA $=0.077)$. After eliminating four items, confirmatory factor analysis testing showed improvement in the four-factor model of the MFI-16 $(\mathrm{CFI}=0.910 ; \mathrm{GFI}=0.909 ; \mathrm{NFI}=0.898, \mathrm{RMSEA}=0.077)$. Internal consistency values were adequate for the total score and four MFI-16 subscales: General fatigue, physical fatigue, reduced activity, and mental fatigue with Cronbach's $\alpha$ range: $0.60-0.82$. The inadequate value (Cronbach's $\alpha=0.43$ ) was received for the subscale of reduced motivation in both MFI-20 and MFI-16. Correlations between the MFI-16 and HADS, STAI, SF-36, and EC measures were statistically significant (all $p^{\prime}$ s $<0.001$ ). Conclusions: The Lithuanian version of the modified MFI of 16 items showed good factorial structure and satisfactory psychometric characteristics, except for reduced motivation subscale.
\end{abstract}

Keywords: coronary artery disease; mental exertion; physical performance; psychometric properties; multidimensional fatigue inventory; fatigue; reliability and validity; rehabilitation

\section{Introduction}

Despite the strides made in medicine, coronary artery disease (CAD) remains the most frequent cause of mortality, accounting for almost one third of all deaths globally [1] and impairing not only the individual's personal life, but also their career and work [2]. Fatigue, which is characterized as a subjective experience of persistent and extreme exhaustion, a lack of energy, and tiredness [3-5] is one of the most frequent and stress-provoking symptoms reported by individuals with heart-related conditions [6-9]. In CAD patients, the prevalence of moderate to severe fatigue reaches $39 \%$ during cardiac rehabilitation (CR), remaining up to $28 \%$ after one year [10]. Up to date, mental fatigue is considered as a risk factor for developing heart diseases [11], while unusual fatigue is a strong predictor of a longer prehospital delay [12], poor health related outcomes, and an increased risk for mortality [13], which is also considered as one of the key prodromal factors in those after acute coronary syndrome (ACS) [14]. Fatigue in those with heart diseases is also common and distressing symptom that raises concerns within the field of occupational health [2]. 
Extensive literature of previously published studies suggests strong associations between fatigue and mental distress [7,8,15-21] as well as poor health-related quality of life (HRQoL) [9] in patients with CAD. Findings in post-ACS patients showed significant associations between fatigue, anxiety and depressive symptoms [7,15,17-19]. A study by Eckhardt et al. [22] reported that symptoms of depression were a sole predictor of fatigue intensity. In fact, some authors suggest that there are great conceptual similarities between the construct of depression and fatigue $[17,23,24]$. Furthermore, previous scientific literature has also drawn the attention towards fatigue and its effect on HRQoL of patients with various clinical conditions [25,26], including heart related conditions [9]. Staniute and colleagues [9] reported that greater limitations due to emotional and physical issues, decreased vitality, poorer social functioning, the perception of worse general health and lower overall HRQoL were significantly linked to greater levels of fatigue. In another study by Burkauskas et al. [8] it was noted that specifically mental, but not other type of fatigue characteristics, was independently associated with worse cognitive functioning in CAD patients during $C R$, drawing the attention to consider not only physical fatigue and exercise capacity (EC), but also mental fatigue as a risk factor for worse health related outcomes.

Considering that almost one third of CAD patients who completed CR program [10] remains significantly fatigued, it is important to detect the presence of fatigue and its characteristics in those individuals early and accurately as well as adapt the CR program accordingly. Optimal treatment of those with fatiguing illnesses requires measuring severity, frequency, duration, the nature and type of fatigue, as this may help to individualize and monitor the progress of therapy focused on reducing symptoms of fatigue [5]. To date, there are at least 25 standardized unidimensional and multidimensional scales designed to assess fatigue in various clinical populations [27,28]. Nevertheless, well-validated instruments in those with heart related conditions, including CAD, are still lacking.

Multidimensional Fatigue Inventory (MFI), created by Smets and colleagues in 1995 [5], was originally intended as the 20-item self-report method to evaluate five domains of fatigue in oncology patients, including general, physical, and mental fatigue, as well as reduced activity and motivation. The MFI is considered as one of the four most valid instruments, meeting the quality assurance requirements and was found to be the most appropriate tool for assessing fatigue in patients with cancer [27].

Furthermore, recent studies suggest the MFI as a useful tool to measure the level of fatigue not only in cancer-related but also in other clinical populations, including patients with hepatitis B infection [29], Hodgkin's lymphoma patients [30], those with a chronic fatigue syndrome [31], idiopathic Parkinson's disease patients [32], fibromyalgia patients [33], individuals with schizophrenia spectrum disorders [34], a major depressive episode [35], multiple sclerosis [36], acquired brain injury [37], pospoliomyelitis syndrome [38], and overall in those that are critically chronically ill and follow intensive care [39]. There were also some attempts to measure validity and reliability of the MFI in 204 patients after myocardial infarction (MI) [40] in a Swedish population, as well as in 201 CAD patients in Brazil [41], suggesting adequate validity and reliability. However, in a larger and more diverse CAD population, the MFI validation studies are very sparse, especially the ones that explore the MFI factorial structure. Nevertheless, the psychometric studies on various self-reported instruments [42,43] in those with heart related conditions are of great importance, as it helps to evaluate the usefulness of the measures and confidently apply research evidence in a clinical work [44].

It is important to note that previous literature has detected several issues regarding the MFI adaptation. Inadequate reliability of the MFI reduced motivation scale was reported in French-Canadian version [45], Swedish version [46], and English version [47,48] of the MFI. Further, in several articles some complications with factorial structure were addressed: the studies of the American [47] and French-Canadian [45] versions of the MFI reported different item loading from the original MFI version of Smets et al. [5], thus did not support the originally proposed structure solution. In the most recent study by Hinz et al. [49] completed in several countries reported incomplete factorial validity of the MFI and the adaptation of the modified MFI was not suggested. These issues suggest that the MFI 
could be further improved and analyzed in the adaptation process of Lithuanian MFI version by applying factor analysis.

The goal of our research was to evaluate psychometric characteristics of the MFI, including the dimensional structure, reliability and validity of the MFI as well as to investigate the dimensional structure in a large sample of Lithuanian CAD patients. In this current study we hypothesized that in CAD patients after ACS (1) The internal reliability of the total fatigue score and the four MFI scales (i.e., general fatigue, physical fatigue, reduced activity, and mental fatigue) will be satisfactory (2) the MFI scores will be associated with mental distress (HADS and STAI) and HRQoL (SF-36), suggesting good convergent validity of the MFI.

\section{Materials and Methods}

\subsection{Study Participants}

For this cross-sectional study, a sum of 1287 consecutive patients with CAD were invited to take part as the study participants from February 2010 to March 2020. This study was conducted as part of the larger ongoing research exploring biopsychosocial and environmental risk factors affecting the course and progression of CAD. Inclusion criteria were (1) a current diagnosis of CAD after recent ACS; (2) attendance of an in-patient cardiovascular rehabilitation (CR) program at the Hospital Palangos klinika, Neuroscience Institute, Lithuanian University of Health Sciences, Palanga, Lithuania. The patients were admitted to the CR program within one week following ACS treatment and gave written informed consent. Exclusion criteria were (1) the unstable cardiovascular condition $(n=62)$, (2) a severe comorbid illness $(n=33)$, and (3) unwillingness to participate in the study $(n=30)$. In total, after exclusion criteria were considered, 1162 participants remained in the final study sample $(76 \%$ men, $24 \%$ women, mean age $57 \pm 9$ years). All the study patients received standard diagnostic and treatment procedures for the secondary prevention of $\mathrm{CAD}$, based on the established guidelines elsewhere [50-53]. The study and its consent procedures were approved by the Regional Biomedical Research Ethics Committee (project identification code: Kardiogen no. 5, 13 April 2007, No. BE-2-21; 15 January 2009, No. P1-38/2007; 12 September 2009, No. P2-38/2007; 20 April 2010, No. P3-38/2007; 24 October 2012, No. P1-110/2012.) This study is also in accordance with the principles of the Declaration of Helsinki.

\subsection{Study Procedure}

Within two days of admission for CR, all study patients were assessed for (1) socio-demographic information, such as gender, age, and education, and (2) clinical characteristics such as New York Heart Association (NYHA) functional class, history of ACS, and angina pectoris class. Further, usual echocardiography testing to assess the left ventricular ejection fraction was performed on all participants of this study. They also performed EC testing. In order to assess HRQoL, the Short Form (36) Health Survey (SF-36) was used [54]. Patients also independently completed questionnaires, assessing their subjective fatigue level (the Multidimensional Fatigue Inventory, MFI-20) [5,7].

Additionally, depressive and anxiety symptoms (Hospital Anxiety and Depression scale, HADS) [55], state and trait anxiety (The Spielberger State-Trait Anxiety Inventory, STAI) [56] were measured in 200 randomly assigned patients. The number of a sample size was reduced to 200 patients for this analysis involving HADS and STAI due to financial limitations regarding licensing fees of these scales. We employed Lithuanian versions of self-rating scales with good psychometric properties, measured in previous studies [9,57-59].

\subsection{Measures}

\subsubsection{Multidimensional Fatigue Inventory, MFI-20}

Fatigue severity was measured by employing subscales from the MFI-20 original version [5,7]. The MFI, consisting 20 items covers five subscales: (1) General fatigue, (2) physical fatigue, (3) mental 
fatigue, (4) reduced activity, and (5) reduced motivation. Each domain consists of four items with possible answers on a five-point ( $1=$ "yes, that is true"; $5=$ "no, that is not true") Likert scale. The domain of General fatigue is composed of the general statements about fatigue and reduced functioning, covering physical as well as psychological aspects of fatigue. Physical fatigue concerns physical feelings related to fatigue. Mental fatigue relates to cognitive functioning, such as concentration difficulties. Reduced activity subscale evaluates the impact of psychological and physical factors on the activity level. The lack of motivation to start an activity is reflected by the subscale of reduced motivation. The total score ranges from 4 to 20 on each subscale, and 20 to 100 for total fatigue score with higher score indicating higher fatigue levels.

\subsubsection{6-Item Short Form Medical Outcome Questionnaire, SF-36}

The SF-36 is comprised of eight subscales that measure HRQoL on eight domains: (1) Physical and (2) social functioning, (3) role limitations due to physical problems, (4) role limitations due to emotional problems, (5) mental health, (6) energy/vitality, (7) pain, and (8) general health perception. Each of the SF-36 domains is rated on scales from 0 to 100, with a higher total score suggesting better HRQoL [54]. Cronbach $\alpha$ coefficients of all eight domains ranges from 0.56 to 0.85 , suggesting adequate internal reliability.

\subsubsection{Exercise Capacity Testing, EC}

The research cardiologist (J.Br.) measured patients' EC with a standardized computer-driven bicycle ergometer (Schiller AT-102). Every three minutes the workload was increased by 25 watts (W) [50]. The peak of workload (PW) in watts (W) or MET (1 MET $=3.5 \mathrm{~mL}$ of oxygen uptake per kilogram of body weight per minute) at the moment of the termination of the exercise test reflected individual's EC. Detailed procedures of EC has been reported in our study elsewhere [60].

\subsubsection{Hospital Anxiety and Depression Scale, HADS}

The self-administered HADS is composed of 14 items, which help to evaluate person's symptoms of anxiety (HADS-A) and depression (HADS-D) [55]. Total scores on both of the subscales is between 0 and 21. The higher total score suggests the worse symptoms of anxiety and depression [61]. Previous studies suggest good psychometric parameters of the HADS in Lithuanian CAD patients [17,62]. In our study, the internal consistency of the HADS was good (Cronbach $\alpha=0.74$; the HADS-A Cronbach $\alpha=0.84)$.

\subsubsection{Spielberger State-Trait Anxiety Inventory, STAI}

The STAI was employed to assess state anxiety (STAI-S, 20 items) and trait anxiety (STAI-T, 20 items) [56]. The higher total score on each subscale represents the higher levels of state and trait anxiety. Having good psychometric characteristics in patients with CAD, STAI has been widely used for research purposes in Lithuania [63-65]. In our study population, the STAI showed good internal consistency (The STAI-S Cronbach's $\alpha=0.92$; the STAI-T Cronbach's $\alpha=0.89$ ).

\subsection{Statistical Analysis}

For statistical procedures, we used The SPSS for Windows statistical package (SPSS Inc., Chicago, IL, USA) (version 17.0). The sample size was determined based on the previous reports by Comrey and Lee [66] as well as MacCallum et al. [67] for sample size in factor analysis. The authors [66,67] suggested that in order to assure adequate recovery of population, minimal sampling error, and stable sample factor analysis solutions, as large as the sample size of $\geq 1000$ participants is preferable, even though the 200-500 sample size in some cases might be acceptable.

Descriptive statistics were generated to define our study population with regards to clinical and sociodemographic characteristics. Floor and ceiling effects were used to demonstrate the response 
distribution and served as a measure of feasibility. If $15 \%$ or more respondents achieve the lowest or highest level of the score on a measure, there may be a significant floor or ceiling effect [68]. We further used skewness statistics, kurtosis statistics, and Shapiro-Wilk tests to evaluate the normality of distribution in the variables.

The internal validity of the five MFI subscales has been calculated using corrected-to-total correlations, inter-item correlations, and $\alpha$-coefficients of Standardized Cronbach. If estimates of a magnitude were higher than 0.7, we considered it as acceptable [69]. The value of the corrected-to-total correlations should be higher than 0.20 and correlations lower than 0.15 are unacceptable [70].

Further, we evaluated convergent validity of the target instrument, while comparing MFI with other related measures administered in the study. Pearson or Spearman correlation coefficients were employed to measure linear associations between the scales of the MFI, the HADS, the STAI, SF-36, and EC measures. Due to financial limitations, to measure the associations between the MFI and the HADS, the STAI, a sample of randomly assigned 200 patients was evaluated.

We used confirmatory factor analysis (CFA) to evaluate whether the original factor structure of the MFI is confirmed for the current sample. The fitness of model with the data was measured by calculating the absolute and comparative fit indices (CFI). Absolute fit indices include chi-square goodness-of-fit (GFI), non-normal fit index (NFI), and root mean square error of approximation (RMSEA). Further analyses resulted in the deletion of 4 items and development of a shortened MFI 16-item version, that helped to improve the factorial structure, while leaving the original number of subscales.

\section{Results}

\subsection{Sample Characteristics}

The final sample was comprised of 1162 CAD patients, 276 women (24\%) and 886 men (76\%); the average age of participants was $57 \pm 9$ years. Table 1 represents socio-demographic, clinical, mental distress characteristics, scores of fatigue, and HRQoL of all study patients. Overall, 87\% of participants met the criteria for NYHA functional class I-II, while 13\% remained within the group of NYHA functional class III. In sum, 37\% of study patients had unstable angina pectoris, and $63 \%$ were admitted after recent acute MI.

Table 1. Sociodemographic and clinical characteristics of all patients.

\begin{tabular}{ccc}
\hline \multirow{2}{*}{ Characteristic } & \multicolumn{2}{c}{$\mathbf{N}=\mathbf{1 1 6 2}$} \\
\cline { 2 - 3 } Age & Mean & SD \\
\hline & 57.34 & 9.09 \\
\hline Gender: & $\mathbf{N}$ & Percent \\
\hline Male & & \\
Female & 886 & 76.2 \\
\hline Education: & 276 & 23.8 \\
\hline Up to 8 years & & \\
High school graduate & 86 & 4.4 \\
College/university degree & 577 & 42.9 \\
\hline Diagnosis: & 499 & 37.0 \\
\hline Unstable angina pectoris & & 63.0 \\
\hline Acute myocardial infarction & 430 & \\
\hline NYHA class: & 732 & 7.4 \\
I & & 79.3 \\
II & 86 & 13.3 \\
\hline III & 921 &
\end{tabular}


Table 1. Cont.

\begin{tabular}{|c|c|c|}
\hline \multirow{2}{*}{ Characteristic } & \multicolumn{2}{|c|}{$\mathrm{N}=1162$} \\
\hline & Mean & SD \\
\hline \multicolumn{3}{|l|}{ HF class: } \\
\hline A & 111 & 9.6 \\
\hline $\mathrm{B}$ & 817 & 70.3 \\
\hline C & 234 & 20.1 \\
\hline Arterial hypertension & 951 & 81.8 \\
\hline \multirow[t]{2}{*}{ Left ventricular ejection fraction $\leq 40 \%$} & 115 & 9.9 \\
\hline & Mean & SD \\
\hline Left ventricular ejection fraction & 51.35 & 8.45 \\
\hline \multirow[t]{2}{*}{ Exercise capacity workload (W) } & 72.90 & 26.95 \\
\hline & $\mathbf{N}$ & Percent \\
\hline \multicolumn{3}{|l|}{ Medication Use: } \\
\hline Nitrates & 267 & 23.0 \\
\hline Beta-blockers & 1027 & 88.4 \\
\hline ACE inhibitors & 941 & 81.0 \\
\hline Diuretics & 169 & 14.5 \\
\hline \multirow[t]{2}{*}{ Benzodiazepines } & 162 & 13.9 \\
\hline & Mean & SD \\
\hline \multicolumn{3}{|l|}{ State Trait Anxiety Inventory: } \\
\hline State anxiety & 37.27 & 10.51 \\
\hline \multirow[t]{2}{*}{ Trait anxiety } & 42.8 & 9.52 \\
\hline & $\mathbf{N}$ & Percent \\
\hline \multicolumn{3}{|l|}{ Anxiety symptoms (HADS-A): } \\
\hline Total score $<8$ & 140 & 70.0 \\
\hline Total score $\geq 8$ & 60 & 30.0 \\
\hline \multicolumn{3}{|l|}{ Depressive symptoms (HADS-D): } \\
\hline Total score $<8$ & 175 & 87.5 \\
\hline \multirow[t]{2}{*}{ Total score $\geq 8$} & 25 & 12.5 \\
\hline & Mean & SD \\
\hline \multicolumn{3}{|l|}{ MFI-20 score } \\
\hline General fatigue & 10.76 & 3.97 \\
\hline Physical fatigue & 11.75 & 4.34 \\
\hline Reduced activity & 12.33 & 3.90 \\
\hline Reduced motivation & 9.91 & 3.43 \\
\hline Mental fatigue & 9.77 & 4.02 \\
\hline Total Fatigue Score & 54.52 & 16.18 \\
\hline \multicolumn{3}{|l|}{ SF-36 } \\
\hline Physical functioning & 68.98 & 19.73 \\
\hline Role limitation due to physical problems & 30.16 & 37.27 \\
\hline Role limitation due to emotional problems & 52.70 & 43.72 \\
\hline Social functioning & 66.84 & 26.24 \\
\hline Mental health & 68.28 & 19.11 \\
\hline Energy/vitality & 59.09 & 20.70 \\
\hline Pain & 51.04 & 27.52 \\
\hline General health perception & 53.15 & 18.86 \\
\hline
\end{tabular}

HADS-A-Anxiety subscale of the Hospital Anxiety and Depression Scale; HADS-D—Depression subscale of the Hospital Anxiety and Depression Scale; NYHA-New York Heart Association; SF-36-Medical Outcomes Study 36-Item Short Form Health Survey; MFI-20-Multidimensional Fatigue Inventory; W-Watts; HF-heart failure. 


\subsection{Reliability of MFI 20-Items, MFI-20}

The results of three reliability tests of all MFI-20 domains are presented in Table 2. The item redundancy was not detected. Inter-item average of correlations for general fatigue domain was 0.46 (range 0.38-0.58); for physical fatigue domain was 0.53 (range $0.44-0.60$ ); for reduced activity domain was 0.40 (0.30-0.47); for reduced motivation domain was 0.24 (0.15-0.35); for mental fatigue domain was $0.49(0.35-0.68)$; and for total score was $0.35(0.10-0.68)$. The internal consistency values were reasonable for the MFI-20 total fatigue score and four of the five domains: General fatigue, physical fatigue, reduced activity and mental fatigue Cronbach's $\alpha$ range: $0.72-0.92$. An inadequate value was found for the domain of reduced motivation (Cronbach's $\alpha=0.55$ ). With regards to the inter-item correlations, a mean value of $\geq 0.20$ was found for the MFI-20 four of the subscales but the lowest correlation was present between items of reduced motivation subscale $(0.24$, range $0.15-0.35)$. Item-total correlations were $\geq 0.20$ for all the subscale of MFI-20 (range: $0.28-0.37$ to range $0.60-0.68$ ).

Table 2. MFI-20 scale item characteristics and internal consistency reliabilities.

\begin{tabular}{|c|c|c|c|c|c|c|c|}
\hline \multirow{2}{*}{$\begin{array}{c}\text { Fatigue } \\
\text { Characteristics }\end{array}$} & \multirow{2}{*}{ Mean } & \multirow{2}{*}{ SD } & \multicolumn{2}{|c|}{ Inter-Item Correlation } & \multirow{2}{*}{$\begin{array}{c}\begin{array}{c}\text { Corrected-to-Total } \\
\text { Correlation }\end{array} \\
\text { Range }\end{array}$} & \multirow{2}{*}{$\begin{array}{c}\begin{array}{c}\text { Coefficient } \alpha \\
\text { (If Item Deleted) }\end{array} \\
\text { Range }\end{array}$} & \multirow{2}{*}{$\begin{array}{l}\text { Standardized } \\
\text { Cronbach's } \alpha\end{array}$} \\
\hline & & & Mean & Range & & & \\
\hline General Fatigue & 10.76 & 3.97 & 0.46 & $(0.38-0.58)$ & $0.52-0.65$ & $0.67-0.75$ & 0.77 \\
\hline Physical Fatigue & 11.75 & 4.34 & 0.53 & $(0.44-0.60)$ & $0.60-0.68$ & $0.76-0.79$ & 0.82 \\
\hline Reduced Activity & 12.33 & 3.90 & 0.40 & $(0.30-0.47)$ & $0.47-0.57$ & $0.63-0.69$ & 0.72 \\
\hline Reduced Motivation & 9.91 & 3.43 & 0.24 & $(0.15-0.35)$ & $0.28-0.37$ & $0.45-0.52$ & 0.55 \\
\hline Mental Fatigue & 9.77 & 4.02 & 0.49 & $(0.35-0.68)$ & $0.46-0.70$ & $0.69-0.73$ & 0.79 \\
\hline Total Fatigue Score & 54.52 & 16.1 & 0.35 & $(0.10-0.68)$ & $0.32-0.72$ & $0.91-0.92$ & 0.92 \\
\hline
\end{tabular}

\subsection{Convergent Validity: Relationships of the Subscales of the MFI-20 to Mental Distress Factors, Functional} Impairment, and Exercise Capacity

Table 3 displays correlations between MFI-20 total score and fatigue subscales and subscales measuring anxiety and depression symptoms (HADS-A, HADS-D), state and trait anxiety (STAI-S, STAI-T), functional impairment (SF-36) and EC. In overall sample, the strongest correlations were found between the MFI general fatigue $(\mathrm{r}=-0.51, p<0.001)$, physical fatigue $(\mathrm{r}=-0.49, p<0.001)$, reduced motivation $(\mathrm{r}=-0.43, p<0.001)$, total fatigue score $(\mathrm{r}=0.551, p<0.001)$, and the SF-36 subscales measuring energy/vitality. In 200 participants, The MFI reduced motivation $(\mathrm{r}=0.50, p<0.001)$, mental fatigue $(\mathrm{r}=0.61, p<0.001)$, and total fatigue score $(\mathrm{r}=0.58, p<0.001)$ were strongly associated with the STAI Trait anxiety, suggesting excellent convergent validity.

Table 3. Convergent Validity: Pearson Correlation Coefficients between the MFI-20, the HADS, the STAI, the SF-36, and EC testing in overall sample.

\begin{tabular}{|c|c|c|c|c|c|c|}
\hline \multirow{3}{*}{$\begin{array}{c}\text { Clinical } \\
\text { Characteristics }\end{array}$} & \multicolumn{5}{|c|}{ MFI-20 } & \multirow{3}{*}{$\begin{array}{c}\text { Total Fatigue } \\
\text { Score }\end{array}$} \\
\hline & $\begin{array}{l}\text { General } \\
\text { Fatigue }\end{array}$ & $\begin{array}{l}\text { Physical } \\
\text { Fatigue }\end{array}$ & $\begin{array}{l}\text { Reduced } \\
\text { Activity }\end{array}$ & $\begin{array}{c}\text { Reduced } \\
\text { Motivation }\end{array}$ & $\begin{array}{l}\text { Mental } \\
\text { Fatigue }\end{array}$ & \\
\hline & \multicolumn{5}{|c|}{$\mathrm{r}(p<0.001)$} & \\
\hline \multicolumn{7}{|l|}{ HADS } \\
\hline Anxiety symptoms & 0.416 & 0.363 & 0.323 & 0.319 & 0.451 & 0.466 \\
\hline Depressive symptoms & 0.551 & 0.509 & 0.484 & 0.525 & 0.533 & 0.563 \\
\hline \multicolumn{7}{|l|}{ STAI } \\
\hline State anxiety & 0.587 & 0.499 & 0.434 & 0.507 & 0.567 & 0.541 \\
\hline Trait anxiety & 0.553 & 0.446 & 0.424 & 0.496 & 0.613 & 0.582 \\
\hline
\end{tabular}


Table 3. Cont.

\begin{tabular}{|c|c|c|c|c|c|c|}
\hline \multirow{3}{*}{$\begin{array}{c}\text { Clinical } \\
\text { Characteristics }\end{array}$} & \multicolumn{5}{|c|}{ MFI-20 } & \multirow{3}{*}{$\begin{array}{c}\text { Total Fatigue } \\
\text { Score }\end{array}$} \\
\hline & $\begin{array}{l}\text { General } \\
\text { Fatigue }\end{array}$ & $\begin{array}{l}\text { Physical } \\
\text { Fatigue }\end{array}$ & $\begin{array}{l}\text { Reduced } \\
\text { Activity }\end{array}$ & $\begin{array}{c}\text { Reduced } \\
\text { Motivation }\end{array}$ & $\begin{array}{l}\text { Mental } \\
\text { Fatigue }\end{array}$ & \\
\hline & \multicolumn{5}{|c|}{$\mathrm{r}(p<0.001)$} & \\
\hline \multicolumn{7}{|l|}{ SF-36 } \\
\hline Physical functioning & -0.459 & -0.446 & -0.386 & -0.355 & -0.299 & -0.475 \\
\hline $\begin{array}{l}\text { Role limitation due to } \\
\text { physical problems }\end{array}$ & -0.290 & -0.304 & -0.273 & -0.229 & -0.172 & -0.310 \\
\hline $\begin{array}{l}\text { Role limitation due to } \\
\text { emotional problem }\end{array}$ & -0.278 & -0.248 & -0.243 & -0.257 & -0.269 & -0.315 \\
\hline Social functioning & -0.376 & -0.341 & -0.300 & -0.288 & -0.296 & -0.391 \\
\hline Mental health & -0.418 & -0.365 & -0.323 & -0.360 & -0.426 & -0.461 \\
\hline Energy/vitality & -0.514 & -0.494 & -0.434 & -0.405 & -0.412 & -0.551 \\
\hline Bodily pain & -0.295 & -0.294 & -0.241 & -0.207 & -0.182 & -0.298 \\
\hline General health & -0.484 & -0.486 & -0.401 & -0.410 & -0.344 & -0.518 \\
\hline Exercise capacity & -0.307 & -0.316 & -0.279 & -0.317 & -0.193 & -0.331 \\
\hline
\end{tabular}

MFI-20—Multidimensional Fatigue Inventory; HADS—-the Hospital Anxiety and Depression Scale; STAI—State Trait Anxiety Inventory; SF-36-Medical Outcomes Study 36-Item Short Form Health Survey.

\subsection{Floor and Ceiling Effects}

We explored the possibility for the floor and ceiling effects in all the MFI-20 subscales as well as for total fatigue score. For the general fatigue subscale, $n=81$ patients $(7 \%)$ had the lowest possible test score, $n=21$ patients $(2 \%)$ had the highest test score. For the physical fatigue subscale, $n=72$ patients $(6 \%)$ had the lowest test score, $n=54(5 \%)$ the highest test score. For the reduced activity, $n=41$ patients ( $3 \%$ ) had the lowest and $n=42$ patients $(4 \%)$ had the highest possible score. For the reduced motivation, $n=66$ patients $(6 \%)$ had the lowest test score, while $n=4$ patients $(0.3 \%)$ had the highest test score. For the mental fatigue, $n=150$ patients $(13 \%)$ had the lowest possible test score, $n=17(1.5 \%)$ had the highest possible test score. For the total fatigue score, $n=16$ patients $(1.4 \%)$ had the lowest test score, $n=1(0.1 \%)$ the highest test score.

\subsection{Factor Analysis of the MFI-20}

We completed a principal components factor analysis using oblique rotation on the MFI-20. The results are presented in Table 4 . In summary, the factor analysis solution was complex. In all four factors, the multiple loadings of items had factor-loading values of $>0.50$. The first factor explained $39 \%$ of the variance in the MFI-20, and was comprised of general fatigue and physical fatigue. The second factor was composed of solely all four mental fatigue items that explained $9 \%$ of the variance of the MFI-20. However, two of the reduced motivation items and one reduced activity item fell on the third factor, which explaining $6 \%$ of the variance of the MFI-20. The fourth factor was loaded by two of the reduced activity items, which explained $5 \%$ of the variance in the MFI-20.

Factor 1 (general/physical), factor 2 (mental fatigue), factor 3 (reduced motivation), and factor 4 (reduced activity) were defined by the authors of the original MFI [5]. General fatigue and physical fatigue were two distinct domains on the original MFI instrument. Surprisingly, confirmatory factor analysis testing of the four-factor model showed acceptable fit (CFI $=0.905 ; \mathrm{GFI}=0.895 ; \mathrm{NFI}=0.893$, RMSEA $=0.077)$. However, of these 20 items, the four items $(3,9,17$, and 18) were difficult to categorize to one specific factor. In other to enhance the factorial structure of the MFI, a second principal components factor analysis with an oblique rotation was completed on the 16 items.

\subsection{Factor Analysis of the 16-Item MFI, MFI-16}

After removing the four items $(3,9,17$ and 18), the factor analysis with multiple loadings of items had factor-loading values $>0.50$ across four factors. Detailed results are presented in Table 5 . 
In short, similarly as with previous factor analysis, the first factor was dominated by general fatigue and physical fatigue that was comprised of eight items. The second factor was composed of all four mental fatigue items. Two of the reduced activity items fell under the third factor, while the fourth factor was loaded by two of the reduced motivation items. Of the 16 items of the MFI-16, the first factor explained $39.7 \%$ of the variance, while the second, third and fourth factors explained $10.2 \%$, $6.9 \%$, and $6.4 \%$ of the variance respectively.

Confirmatory factor analysis testing of the four-factor model from 16 items of the MFI-20 showed acceptable fit $(\mathrm{CFI}=0.910 ; \mathrm{GFI}=0.909 ; \mathrm{NFI}=0.898, \mathrm{RMSEA}=0.077)$ (Table 5).

Table 4. Factor analysis of the Multidimensional Fatigue Inventory (MFI) 20-item responses.

\begin{tabular}{|c|c|c|c|c|}
\hline \multirow{2}{*}{ Fatigue Characteristics and Items } & \multicolumn{4}{|c|}{ Factors } \\
\hline & 1 & 2 & 3 & 4 \\
\hline \multicolumn{5}{|l|}{ General Fatigue } \\
\hline I feel fit & 0.529 & & & \\
\hline I feel tired & 0.726 & & & \\
\hline I feel rested & 0.526 & & & \\
\hline I tired easily & 0.723 & & & \\
\hline \multicolumn{5}{|l|}{ Physical Fatigue } \\
\hline Physically I feel I am in a bad condition & 0.642 & & & \\
\hline Physically I feel I am in an excellent condition & 0.619 & & & \\
\hline Physically I feel I am in a bad condition & 0.737 & & & \\
\hline Physically I can take on a lot & 0.658 & & & \\
\hline \multicolumn{5}{|l|}{ Reduced Activity } \\
\hline I feel very active & & & 0.609 & \\
\hline I think I do a lot in a day & & & & 0.658 \\
\hline I think I do very little in a day & & & & 0.774 \\
\hline I get little done & 0.607 & & & \\
\hline \multicolumn{5}{|l|}{ Reduced Motivation } \\
\hline I feel like doing all sorts of nice things & & & 0.630 & \\
\hline I dread having to do things & & & & \\
\hline I have a lot of plans & & & 0.594 & \\
\hline I don't feel like doing anything & & & & \\
\hline \multicolumn{5}{|l|}{ Mental Fatigue } \\
\hline When I am doing something, I can keep my thoughts on it & & 0.706 & & \\
\hline I can concentrate well & & 0.750 & & \\
\hline It takes a lot of effort to concentrate on things & & 0.772 & & \\
\hline My thoughts easily wander & & 0.626 & & \\
\hline Alpha & 0.90 & 0.79 & 0.66 & 0.60 \\
\hline
\end{tabular}

Note: Extraction Method: Principal Component Analysis. Rotation Method: Varimax with Kaiser Normalization. Factor loadings less than 0.5 were not listed in the table. Kaiser-Meyer-Olkin index $=0.937, p$-value for Bartlett's Test of Sphericity is less than 0.001. Cumulative percent of explained variance is $59.3 \%$.

Table 5. Factor analysis of Multidimensional Fatigue Inventory (MFI) 16-items responses.

\begin{tabular}{ccccc}
\hline Fatigue Characteristics and Items & \multicolumn{4}{c}{ Factors } \\
\cline { 2 - 4 } & $\mathbf{1}$ & $\mathbf{2}$ & $\mathbf{3}$ & $\mathbf{4}$ \\
\hline General Fatigue & & & \\
\hline I feel fit & 0.588 & & \\
I feel tired & 0.739 & & \\
I feel rested & 0.579 & \\
I tired easily & 0.739 & \\
\hline
\end{tabular}


Table 5. Cont.

\begin{tabular}{|c|c|c|c|c|}
\hline \multirow{2}{*}{ Fatigue Characteristics and Items } & \multicolumn{4}{|c|}{ Factors } \\
\hline & 1 & 2 & 3 & 4 \\
\hline \multicolumn{5}{|l|}{ Physical Fatigue } \\
\hline Physically I feel I am in a bad condition & 0.660 & & & \\
\hline Physically I feel I am in an excellent condition & 0.673 & & & \\
\hline Physically I feel I am in a bad condition & 0.757 & & & \\
\hline Physically I can take on a lot & 0.716 & & & \\
\hline \multicolumn{5}{|l|}{ Reduced Activity } \\
\hline I think I do a lot in a day & & & 0.745 & \\
\hline I think I do very little in a day & & & 0.796 & \\
\hline \multicolumn{5}{|l|}{ Reduced Motivation } \\
\hline I feel like doing all sorts of nice things & & & & 0.555 \\
\hline I have a lot of plans & & & & 0.732 \\
\hline \multicolumn{5}{|l|}{ Mental Fatigue } \\
\hline When I am doing something, I can keep my thoughts on it & & 0.736 & & \\
\hline I can concentrate well & & 0.790 & & \\
\hline It takes a lot of effort to concentrate on things & & 0.772 & & \\
\hline My thoughts easily wander & & 0.638 & & \\
\hline Alpha & 0.89 & 0.79 & 0.60 & 0.43 \\
\hline
\end{tabular}

Note: Extraction Method: Principal Component Analysis; Rotation Method: Varimax with Kaiser Normalization. Factor loadings less than 0.5 were not listed in the table. Kaiser-Meyer-Olkin index $=0.919, p$-value for Bartlett's Test of Sphericity is less than 0.001 . Cumulative percent of explained variance is $63.2 \%$.

\subsection{Reliability of MFI-16}

The summary of the results of three reliability tests for the all MFI-16 domains is presented in Table 6. Inter-item correlations averaged 0.46 (range 0.38-0.58) for general fatigue, 0.53 (range 0.44-0.60) for physical fatigue, 0.43 for reduced activity, 0.27 for reduced motivation, $0.49(0.35-0.68)$ for mental fatigue, and $0.35(0.12-0.68)$ for total fatigue score. The internal consistency values were reasonable for the MFI-16 total fatigue score and four of the five subscales: General fatigue, Physical fatigue, Reduced activity, and Mental fatigue Cronbach's $\alpha$ range: $0.60-0.89$. Cronbach's $\alpha=0.43$ was received for the domain of reduced motivation, suggesting inadequate internal reliability. In terms of the inter-item correlations, a mean value of $\geq 0.20$ was calculated for the MFI- 16 four of the subscales but the lowest correlation was present between items of reduced motivation subscale (0.24). Item-total correlations were $\geq 0.20$ for all the subscales of MFI- 16 .

Table 6. Multidimensional Fatigue Inventory (MFI) 16-items characteristics and internal consistency reliabilities.

\begin{tabular}{|c|c|c|c|c|c|c|c|}
\hline \multirow{2}{*}{$\begin{array}{c}\text { Fatigue } \\
\text { Characteristics }\end{array}$} & \multirow{2}{*}{ Mean } & \multirow{2}{*}{ SD } & \multicolumn{2}{|c|}{ Inter-Item Correlation } & \multirow{2}{*}{$\begin{array}{c}\text { Corrected-to-Total } \\
\text { Correlation }\end{array}$} & \multirow{2}{*}{$\begin{array}{c}\begin{array}{c}\text { Coefficient } \alpha \\
\text { (If Item Deleted) }\end{array} \\
\text { Range }\end{array}$} & \multirow{2}{*}{$\begin{array}{l}\text { Standardized } \\
\text { Cronbach's }\end{array}$} \\
\hline & & & Mean & Range & & & \\
\hline Physical Fatigue & 11.75 & 4.34 & 0.53 & $0.44-0.60$ & $0.60-0.68$ & $0.76-0.79$ & 0.82 \\
\hline Reduced Activity & 6.45 & 2.26 & 0.43 & - & 0.43 & - & 0.60 \\
\hline Mental Fatigue & 9.77 & 4.02 & 0.49 & $0.35-0.68$ & $0.46-0.70$ & $0.69-0.73$ & 0.79 \\
\hline Total Fatigue Score & 43.99 & 13.03 & 0.35 & $0.12-0.68$ & $0.14-0.58$ & $0.83-0.90$ & 0.89 \\
\hline
\end{tabular}


3.8. Convergent Validity: Relationships of the Factors of the MFI-16 to Mental Distress Factors, HRQOL, and Exercise Capacity

To evaluate convergent validity in the overall sample, we measured the associations between the MFI-16 and other related constructs. Specifically, Table 7 displays the significant associations between the factors of MFI-16 and subscales measuring anxiety and depressive symptoms (HADS-A, HADS-D), state and trait anxiety (STAI-S, STAI-T), functional impairment (SF-36) and EC. In total sample, the strongest correlations were found between Factor 1 (general/physical fatigue) $(\mathrm{r}=-0.53$, $p<0.001)$, Factor 3 (reduced activity) $(r=-0.28, p<0.001)$ and the SF-36 subscales measuring energy/vitality. In 200 patients, Factor 2 (mental fatigue) $(r=0.61, p<0.001)$ and Factor 4 (reduced motivation) $(\mathrm{r}=0.41, p<0.001)$ were most strongly correlated with the STAI-T (trait anxiety) and HADS-D (depressive symptoms), suggesting excellent convergent validity. The total fatigue score was most strongly associated with depressive symptoms $(r=0.56, p<0.001)$ and trait anxiety $(r=0.58$, $p<0.001)$.

Table 7. Convergent validity: Pearson Correlation Coefficients between the factors of Multidimensional Fatigue Inventory (MFI) 16-items, the HADS, the STAI, the SF-36, and exercise capacity in the overall sample.

\begin{tabular}{|c|c|c|c|c|c|}
\hline \multirow{3}{*}{ Clinical Characteristics } & \multicolumn{4}{|c|}{ Factors } & \multirow{3}{*}{$\begin{array}{c}\text { Total Fatigue } \\
\text { Score }\end{array}$} \\
\hline & 1 & 2 & 3 & 4 & \\
\hline & \multicolumn{4}{|c|}{$\mathrm{r}(p<0.001)$} & \\
\hline \multicolumn{6}{|l|}{ HADS } \\
\hline Anxiety & 0.410 & 0.451 & 0.304 & 0.177 & 0.461 \\
\hline Depressive symptoms & 0.558 & 0.533 & 0.374 & 0.424 & 0.561 \\
\hline \multicolumn{6}{|l|}{ STAI } \\
\hline State anxiety & 0.570 & 0.567 & 0.342 & 0.381 & 0.539 \\
\hline Trait anxiety & 0.524 & 0.613 & 0.333 & 0.407 & 0.576 \\
\hline \multicolumn{6}{|l|}{ SF-36 } \\
\hline Physical functioning & -0.478 & -0.299 & -0.237 & -0.244 & -0.461 \\
\hline Role limitation due to physical problems & -0.315 & -0.172 & -0.180 & -0.155 & -0.299 \\
\hline Role limitation due to emotional problem & -0.277 & -0.269 & -0.161 & -0.150 & -0.302 \\
\hline Social functioning & -0.378 & -0.296 & -0.197 & -0.216 & -0.388 \\
\hline Mental health & -0.413 & -0.426 & -0.217 & -0.246 & -0.458 \\
\hline Energy/vitality & -0.532 & -0.412 & -0.282 & -0.326 & -0.549 \\
\hline Bodily pain & -0.311 & -0.182 & -0.180 & -0.121 & -0.294 \\
\hline General health & -0.512 & -0.344 & -0.264 & -0.329 & -0.514 \\
\hline Exercise capacity & -0.329 & -0.193 & -0.185 & -0.232 & -0.315 \\
\hline
\end{tabular}

HADS-the Hospital Anxiety and Depression Scale; STAI-State Trait Anxiety Inventory; SF-36-Medical Outcomes Study 36-Item Short Form Health Survey; Factor 1-General/Physical fatigue; Factor 2-Mental fatigue; Factor 3-Reduced activity; Factor 4-Reduced motivation.

\section{Discussion}

The purpose of our research was to measure reliability and validity of the MFI as well as to investigate the dimensional structure in the sample of CAD patients after recent ACS. We hypothesized that (1) the internal consistency of a total score and the four MFI domains (i.e., general fatigue, physical fatigue, reduced activity, and mental fatigue) will be satisfactory, and (2) the subjective fatigue (as measured by the MFI) will be linked with mental distress (as measured by HADS and STAI). Both of the hypothesis were met after the completion of the statistical analysis.

The multidimensional structure of the MFI has been found to be comprised of four factors, including general/physical fatigue, mental fatigue, reduced activity, and reduced motivation. The four-factor model used in our study was in line with the original results of Smets et al. [5]. Nevertheless, several 
issues with the factorial structure were identified. Two items of the original MFI-20 loaded on unexpected dimensions, while the other two did not meet the criteria for factor-loading values $>0.50$ across the four factors. These inconsistent loading were also reported in previous studies [45,47], suggesting the possibility for further modifications. Respecting the original four factor structure suggested by the MFI-20 authors [5], in the current study, we eliminated the following items (items 3, 9, 17, and 18). After the noted modifications, MFI-16 was an improved version in terms of the factorial structure and confirmatory support was reached, showing acceptable fit. The MFI 16-item four-factor model was further employed to evaluate the internal consistency of all factors.

In terms of factor loadings, even though several previous studies have reported five-factor model of MFI [30,31] or incomplete factorial validity [49], in our study we found that the domains of General fatigue and the domain of Physical fatigue were highly correlated and fell under the same factor. The four-factor model of the MFI appears to be more common in scientific literature and is in accordance with the original study by Smets et al. [5], as well as with other more recent studies [30,37,45,46,71]. It is previously suggested that due to subjective patients' experience, it might be hard to distinguish between general and physical aspects of fatigue [46]. Nevertheless, the decision whether it is better to merge these two subscales or keep them as separate subscales remained an open question even for the original authors [5]. Based on our study results, the option to merge the General and Physical fatigue subscales of the MFI is recommended when measuring fatigue in those with CAD. However, the five subscales can also be retained, until more data is gathered as suggested by original authors [5].

Furthermore, in our study, we tested the reliability of the MFI-20 and modified version the MFI-16 while using inter-item correlations, corrected item-to-total correlations and Cronbach's $\alpha$ values. Inter-item correlations and corrected-to-total correlations suggested adequate reliability. All factors showed moderate to acceptable [69] Cronbach $\alpha$ coefficients ranging from 0.60 to 0.82 , except for reduced motivation factor (Cronbach $\alpha=0.43$ ). The lower Cronbach $\alpha$ coefficient for reduced motivation factor is consistent with previous findings [45-48], thus the results of a current study might not be caused due to cultural differences but rather reflects the psychometric properties of the MFI-20. Nevertheless, further investigation for reduced motivation subscale is necessary to address this issue. Overall, the current study suggests adequate reliability for the MFI, except for one subscale of reduced motivation.

Further, the current study has also shown that convergent validity of Lithuanian MFI-20 as well as modified MFI-16 is good: Each subscale and factor was correlated with closely related constructs of mental distress (anxiety and depressive symptoms (HADS-A, HADS-D), state and trait anxiety (STAI-S, STAI-T)), HRQoL as presented by all SF-36 subscales, as well as the level of objective EC (all $p^{\prime} \mathrm{s} \leq 0.001$ ). Our findings are in line with the previous research by Smets et al. [72] Fillion et al. [45], Lin et al. [31] in terms of showing high correlations with previously mentioned mental distress and HRQoL scales.

Additionally, we have also investigated floor and ceiling effect for the MFI. Our findings yielded plausible results as no ceiling or floor effects were detected. Similarly, in a recent study by Antonio et al. [41] it was found that $2.5 \%$ of the CAD patients reported lowest point on total fatigue score, while none has scored the highest score. In our study we expanded the knowledge and further explored not only floor and ceiling affects for a total fatigue score but also for separate domains, where participants number with the lowest scores ranged from 3 to $13 \%$ and with the highest scores ranged from 0.3 to $5 \%$. Thus, in none of the domains participants number topped $15 \%$ indicating a significant floor or ceiling effect [68].

Several ideas may explain the inconsistent factorial structure of the MFI-20 items and the need to eliminate four items in order to improve the dimensional structure. First, all our patients had been in the CR for only two weeks, thus questions like "I get little done" (question 17) or "I feel very active" (question 3) might have been answered based on the changed context of physical settings, rather than internal state and health condition. Secondly, due to cultural differences and subjective understanding of fatiguing experience, questions like "I dread having do things" (question 9) or "I don't feel like doing anything" might have been attributed to somewhat different concept than reduced motivation, possibly to symptomatology of CAD. 
From occupational health perspective, up to $91 \%$ of the CAD patients after CR [73] returns to the workplace, while successful vocational reintegration is essential to those individuals and their psychosocial functioning [74]. Up till now, occupational therapists have been using various instruments, including those that assess anxiety and depressive symptoms as well as health related outcome measures of former CAD patients [74]. The MFI could serve as a useful instrument for evaluating and monitoring different fatigue characteristics in individuals with CAD that could further assist in tailoring individualized work conditions, workload or daily schedule that may help them to better adapt to their health changes at work.

\subsection{Study Limitations}

Despite of our consistent findings, several limitations should be noted. First, test-retest reliability was not evaluated, precluding us from making interpretation on replicability of the given results more than once in the same population. Secondly, the study was completed in a large cohort of Lithuanian CAD patients, thus generalizability for other cultural cohorts should be assumed and interpreted with caution. Finally, even though we achieved the original four factor structure, to meet this assumption, the adjustment had to be completed and the original 20-item MFI was reduced to 16-items. Despite the potential limitation, our study included a large sample size of CAD patients, suggesting high confidence of generalizability of the results in Lithuanian patients with CAD.

\subsection{Future Directions}

Even though the MFI is a commonly used instrument, its structure still struggles to find perfect suitability among the various diseases and cultural adaptations. In order to address these issues, we developed a shorter MFI version of 16 items with good factorial structure and sound psychometric qualities. Nevertheless, further studies in various clinical samples are warranted to further address the issues related to the MFI psychometric properties, especially factorial structure, and internal consistency of reduced motivation subscale. Considering the validity of the MFI, the improvements in the future studies can be made in terms of random selections of the CAD patients as well as studies in more diverse cultural cohorts, allowing the clinicians and researchers in related fields to draw more confident conclusions for the generalizability of the study results.

\section{Conclusions}

This is the first study showing the MFI as an adequate instrument to evaluate the level of fatigue in Lithuanian clinical settings. Nevertheless, the modified MFI version of MFI-16 can be considered as psychometrically improved instrument to measure the multidimensional construct of fatigue, as it was found to have a sound and complete factorial structure in CAD patients. MFI-16 may assist in early detection and characterization of fatigue in cardiac patients undergoing cardiovascular rehabilitation after recent acute coronary event. This may help to tailor individualized treatment program and to not only reduce the levels of fatigue but also positively affect patients' health related quality of life and emotional state, including depressive and anxiety symptoms.

This latest questionnaire is tailored to CAD patients, and clinicians should find it useful to test the fatigue of these patients. However, the subscale of reduced motivation should be considered with caution due to possible threat to internal consistency.

Author Contributions: Conceptualization, J.G.-S.; methodology, J.G.-S., N.K.; validation, J.G.-S., N.K.; formal analysis, J.G.-S., N.K.; investigation, J.G.-S.; data curation, N.K.; writing—original draft preparation, J.G.-S., N.K.; writing-review and editing, A.B., J.B. (Julius Burkauskas); supervision, J.B. (Julija Brozaitiene), A.B., N.M., and J.N.; project administration N.K., J.B. (Julius Burkauskas). All authors have read and agreed to the published version of the manuscript.

Funding: This research received no external funding.

Acknowledgments: The authors are grateful for staff of the Laboratory of Behavioral Medicine for their contribution in collecting the data for this study as well as statistician Elena Bovina for her great help in statistical 
procedures. The work of Julius Burkauskas was partially funded by the European Social Fund under the No 09.3.3-LMT-K-712 “Development of Competences of Scientists, other Researchers and Students through Practical Research Activities" measure.

Conflicts of Interest: None of the authors declare any conflict of interests except Julija Gecaite-Stonciene, who works as a consultant at Facit, LLC and Julius Burkauskas, who has been a consultant to Cogstate, Ltd. This research has not received specific grants from any funding agency in the public, commercial, or from-for-profit sectors.

\section{References}

1. Al-Mallah, M.H.; Sakr, S.; Al-Qunaibet, A. Cardiorespiratory fitness and cardiovascular disease prevention: An update. Curr. Atheroscler. Rep. 2018, 20, 1. [CrossRef] [PubMed]

2. Price, A.E. Heart disease and work. Heart 2004, 90, 1077-1084. [CrossRef] [PubMed]

3. Aaronson, L.S.; Teel, C.S.; Cassmeyer, V.; Neuberger, G.B.; Pallikkathayil, L.; Pierce, J.; Press, A.N.; Williams, P.D.; Wingate, A. Defining and measuring fatigue. Image J. Nurs. Scholarsh. 1999, 31, 45-50. [CrossRef] [PubMed]

4. Ream, E.; Richardson, A. Fatigue: A concept analysis. Int. J. Nurs. Stud. 1996, 33, 519-529. [CrossRef]

5. Smets, E.; Garssen, B.; Bonke, B.D.; de Haes, J. The Multidimensional Fatigue Inventory (MFI) psychometric qualities of an instrument to assess fatigue. J. Psychosom. Res. 1995, 39, 315-325. [CrossRef]

6. Williams, B.A. The clinical epidemiology of fatigue in newly diagnosed heart failure. BMC Cardiovasc. Disord. 2017, 17, 122. [CrossRef]

7. Bunevicius, A.; Stankus, A.; Brozaitiene, J.; Girdler, S.S.; Bunevicius, R. Relationship of fatigue and exercise capacity with emotional and physical state in patients with coronary artery disease admitted for rehabilitation program. Am. Heart J. 2011, 162, 310-316. [CrossRef]

8. Burkauskas, J.; Bunevicius, A.; Brozaitiene, J.; Neverauskas, J.; Fineberg, N.A.; Wellsted, D.; Bunevicius, R.; Mickuviene, N. Exploring cognitive concomitants of mental fatigue in patients with coronary artery disease. Neuropsychobiology 2017, 76, 151-160. [CrossRef]

9. Staniute, M.; Bunevicius, A.; Brozaitiene, J.; Bunevicius, R. Relationship of health-related quality of life with fatigue and exercise capacity in patients with coronary artery disease. Eur. J. Cardiovasc. Nurs. J. Work. Group Cardiovasc. Nurs. Eur. Soc. Cardiol. 2014, 13, 338-344. [CrossRef]

10. Van Geffen, M.E.; Ter Hoeve, N.; Sunamura, M.; Stam, H.J.; van Domburg, R.T.; van den Berg-Emons, R.J. Fatigue during and after cardiac rehabilitation. J. Rehabil. Med. 2015, 47, 569-574. [CrossRef]

11. Guan, S.; Xiaerfuding, X.; Ning, L.; Lian, Y.; Jiang, Y.; Liu, J.; Ng, T.B. Effect of job strain on job burnout, mental fatigue and chronic diseases among civil servants in the xinjiang uygur autonomous region of China. Int. J. Environ. Res. Public Health 2017, 14, 872. [CrossRef]

12. Zègre-Hemsey, J.K.; Burke, L.A.; de Von, H.A. Patient-reported symptoms improve prediction of acute coronary syndrome in the emergency department. Res. Nurs. Health 2018, 41, 459-468. [CrossRef]

13. Irvine, J.; Basinski, A.; Baker, B.; Jandciu, S.; Paquette, M.; Cairns, J.; Connolly, S.; Roberts, R.; Gent, M.; Dorian, P.; et al. Depression and risk of sudden cardiac death after acute myocardial infarction: Testing for the confounding effects of fatigue. Psychosom. Med. 1999, 61, 729-737. [CrossRef] [PubMed]

14. McSweeney, J.C.; Crane, P.B. Challenging the rules: Women's prodromal and acute symptoms of myocardial infarction. Res. Nurs. Health 2000, 23, 135-146. [CrossRef]

15. Alsén, P.; Brink, E.; Brändström, Y.; Karlson, B.W.; Persson, L.O. Fatigue after myocardial infarction: Relationships with indices of emotional distress, and sociodemographic and clinical variables. Int. J. Nurs. Pract. 2010, 16, 326-334. [CrossRef] [PubMed]

16. Asensio-Cuesta, S.; Bresó, A.; Saez, C.; García-Gómez, J.M. Robustness and findings of a web-based system for depression assessment in a university work context. Int. J. Environ. Res. Public Health 2019, 16, 644. [CrossRef] [PubMed]

17. Bunevicius, A.; Brozaitiene, J.; Stankus, A.; Bunevicius, R. Specific fatigue-related items in self-rating depression scales do not bias an association between depression and fatigue in patients with coronary artery disease. Gen. Hos. Psychiatry 2011, 33, 527-529. [CrossRef]

18. Falk, K.; Patel, H.; Swedberg, K.; Ekman, I. Fatigue in patients with chronic heart failure-A burden associated with emotional and symptom distress. Eur. J. Cardiovasc. Nurs. 2009, 8, 91-96. [CrossRef]

19. Johansson, I.; Karlson, B.W.; Grankvist, G.; Brink, E. Disturbed sleep, fatigue, anxiety and depression in myocardial infarction patients. Eur. J. Cardiovasc. Nurs. 2010, 9, 175-180. [CrossRef] 
20. Kim, H.; Son, H. Fatigue-related factors for community-dwelling older adults with diabetes: A theory-guided multi-dimensional approach using the dynamic biopsychosocial model. Int. J. Environ. Res. Public Health 2019, 16, 4502. [CrossRef]

21. Plach, S.K.; Heidrich, S.M.; Jeske, L. Fatigue representations in women with heart failure. Res. Nurs. Health 2006, 29, 452-464. [CrossRef]

22. Eckhardt, A.L.; Devon, H.A.; Piano, M.R.; Ryan, C.J.; Zerwic, J.J. Fatigue in the presence of coronary heart disease. Nurs. Res. 2014, 63, 83-93. [CrossRef]

23. Fuller-Thomson, E.; Nimigon, J. Factors associated with depression among individuals with chronic fatigue syndrome: Findings from a nationally representative survey. Fam. Pract. 2008, 25, 414-422. [CrossRef] [PubMed]

24. Nater, U.M.; Lin, J.M.; Maloney, E.M.; Jones, J.F.; Tian, H.; Boneva, R.S.; Raison, C.L.; Reeves, W.C.; Heim, C. Psychiatric comorbidity in persons with chronic fatigue syndrome identified from the Georgia population. Psychosom. Med. 2009, 71, 557-565. [CrossRef]

25. Mundo-López, A.; Ocón-Hernández, O.; San-Sebastián, A.P.; Galiano-Castillo, N.; Rodríguez-Pérez, O.; Arroyo-Luque, M.S.; Arroyo-Morales, M.; Cantarero-Villanueva, I.; Fernández-Lao, C.; Artacho-Cordón, F.; et al. Contribution of chronic fatigue to psychosocial status and quality of life in spanish women diagnosed with endometriosis. Int. J. Environ. Res. Public Health 2020, 17, 3831. [CrossRef] [PubMed]

26. Álvarez-Salvago, F.; Lara-Ramos, A.; Cantarero-Villanueva, I. Chronic fatigue, physical impairments and quality of life in women with endometriosis: A case-control study. Int. J. Environ. Res. Public Health 2020, 17, 3610. [CrossRef] [PubMed]

27. Al Maqbali, M.; Hughes, C.; Gracey, J.; Rankin, J.; Dunwoody, L.; Hacker, E. Quality assessment criteria: Psychometric properties of measurement tools for cancer related fatigue. Acta Oncol. 2019, 58, 1286-1297. [CrossRef]

28. Shahid, A.; Shen, J.; Shapiro, C.M. Measurements of sleepiness and fatigue. J. Psychosom. Res. 2010, 69, 81-89. [CrossRef]

29. Saffari, M.; Naderi, M.K.; Piper, C.N.; Koenig, H.G. Multidimensional fatigue inventory in people with hepatitis B infection. Gastroenterol. Nurs. 2017, 40, 380-392. [CrossRef]

30. Baptista, R.L.R.; Biasoli, I.; Scheliga, A.; Soares, A.; Brabo, E.; Morais, J.C.; Werneck, G.L.; Spector, N. Psychometric properties of the multidimensional fatigue inventory in Brazilian Hodgkin's lymphoma survivors. J. Pain Symptom Manag. 2012, 44, 908-915. [CrossRef]

31. Lin, J.M.S.; Brimmer, D.J.; Maloney, E.M.; Nyarko, E.; BeLue, R.; Reeves, W.C. Further validation of the Multidimensional Fatigue Inventory in a US adult population sample. Popul. Health Metr. 2009, 7, 18. [CrossRef] [PubMed]

32. Elbers, R.G.; van Wegen, E.E.H.; Verhoef, J.; Kwakkel, G. Reliability and structural validity of the Multidimensional Fatigue Inventory (MFI) in patients with idiopathic Parkinson's disease. Parkinsonism Relat. Dis. 2012, 18, 532-536. [CrossRef] [PubMed]

33. Munguía-Izquierdo, D.; Segura-Jiménez, V.; Camiletti-Moirón, D.; Pulido-Martos, M.; Alvarez-Gallardo, I.; Romero, A.; Aparicio, V.; Carbonell-Baeza, A.; Delgado-Fernández, M. Multidimensional Fatigue Inventory: Spanish adaptation and psychometric properties for fibromyalgia patients. The Al-Andalus study. Clin. Exp. Rheumatol. 2012, 30, 94-102. [PubMed]

34. Hedlund, L.; Gyllensten, A.L.; Hansson, L. A psychometric study of the multidimensional fatigue inventory to assess fatigue in patients with schizophrenia spectrum disorders. Community Mental Health J. 2015, 51, 377-382. [CrossRef] [PubMed]

35. Chung, K.F.; Yu, B.Y.M.; Yung, K.P.; Yeung, W.F.; Ng, T.H.; Ho, F.Y.Y. Assessment of fatigue using the Multidimensional Fatigue Inventory in patients with major depressive disorder. Compr. Psychiatry 2014, 55, 1671-1678. [CrossRef]

36. Bol, Y.; Duits, A.A.; Vertommen-Mertens, C.E.R.; Hupperts, R.M.M.; Romberg-Camps, M.J.L.; Verhey, F.R.J.; Vlaeyen, J.W.S. The contribution of disease severity, depression and negative affectivity to fatigue in multiple sclerosis: A comparison with ulcerative colitis. J. Psychosom. Res. 2010, 69, 43-49. [CrossRef]

37. Manoli, R.; Chartaux-Danjou, L.; Delecroix, H.; Daveluy, W.; Moroni, C. Is multidimensional fatigue inventory (MFI-20) adequate to measure brain injury related fatigue? Disabil. Health J. 2020, 13, 100913. [CrossRef]

38. Lexell, J.; Jonasson, S.B.; Brogardh, C. Psychometric properties of three fatigue rating scales in individuals with late effects of polio. Ann. Rehabil. Med. 2018, 42, 702-712. [CrossRef] 
39. Wintermann, G.B.; Rosendahl, J.; Weidner, K.; Strauß, B.; Hinz, A.; Petrowski, K. Fatigue in chronically critically ill patients following intensive care-reliability and validity of the multidimensional fatigue inventory (MFI-20). Health Qual. Life Outcomes 2018, 16, 37. [CrossRef]

40. Fredriksson-Larsson, U.; Brink, E.; Alsén, P.; Falk, K.; Lundgren-Nilsson, Å. Psychometric analysis of the Multidimensional Fatigue Inventory in a sample of persons treated for myocardial infarction. J. Nurs. Meas. 2015, 23, 154-167. [CrossRef]

41. Antonio, D.A.F.; Muller, A.G. Reliability and viability of using the Multidimensional Fatigue Inventory-20 in patients with chronic coronary artery disease. Rev. Esc. Enferm. USP 2019, 53, e03511. [CrossRef] [PubMed]

42. Mazoteras Pardo, V.; Losa Iglesias, M.E.; López Chicharro, J.; Becerro de Bengoa Vallejo, R. The qardioarm app in the assessment of blood pressure and heart rate: Reliability and validity study. JMIR $m$ Health $u$ Health 2017, 5, e198. [CrossRef] [PubMed]

43. Mazoteras-Pardo, V.; Becerro-De-Bengoa-Vallejo, R.; Losa-Iglesias, M.E.; López-López, D.; Palomo-López, P.; Rodríguez-Sanz, D.; Calvo-Lobo, C. The qardioarm blood pressure app for self-measurement in an obese population: Validation study using the european society of hypertension international protocol revision 2010. JMIR mHealth uHealth 2018, 6, e11632. [CrossRef] [PubMed]

44. Zangaro, G.A. Importance of reporting psychometric properties of instruments used in nursing research. West. J. Nurs.Res. 2019, 41, 1548-1550. [CrossRef] [PubMed]

45. Fillion, L.; Gélinas, C.; Simard, S.; Savard, J.; Gagnon, P. Validation evidence for the French Canadian adaptation of the Multidimensional Fatigue Inventory as a measure of cancer-related fatigue. Cancer Nurs. 2003, 26, 143-154. [CrossRef]

46. Lundh Hagelin, C.; Wengström, Y.; Runesdotter, S.; Johan Fürst, C. The psychometric properties of the Swedish Multidimensional Fatigue Inventory MFI-20 in four different populations. Acta Oncol. 2007, 46, 97-104. [CrossRef]

47. Meek, P.M.; Nail, L.M.; Barsevick, A.; Schwartz, A.L.; Stephen, S.; Whitmer, K.; Beck, S.L.; Jones, L.S.; Walker, B.L. Psychometric testing of fatigue instruments for use with cancer patients. Nurs. Res. 2000, 49, 181-190. [CrossRef]

48. Schneider, R.A. Reliability and validity of the multidimensional fatigue inventory (MFI-20) and the rhoten fatigue scale among rural cancer outpatients. Cancer Nurs. 1998, 21, 370-373. [CrossRef]

49. Hinz, A.; Benzing, C.; Brähler, E.; Zenger, M.; Herzberg, P.Y.; Finck, C.; Schmalbach, B.; Petrowski, K. Psychometric properties of the multidimensional fatigue inventory (MFI-20), derived from seven samples. J. Pain Symptom. Manag. 2020, 59, 717-723. [CrossRef]

50. Fletcher, G.F.; Ades, P.A.; Kligfield, P.; Arena, R.; Balady, G.J.; Bittner, V.A.; Coke, L.A.; Fleg, J.L.; Forman, D.E.; Gerber, T.C.; et al. Exercise standards for testing and training: A scientific statement from the American Heart Association. Circulation 2013, 128, 873-934. [CrossRef]

51. Piepoli, M.F.; Corra, U.; Benzer, W.; Bjarnason-Wehrens, B.; Dendale, P.; Gaita, D.; McGee, H.; Mendes, M.; Niebauer, J.; Zwisler, A.D.; et al. Secondary prevention through cardiac rehabilitation: From knowledge to implementation. A position paper from the cardiac rehabilitation section of the European Association of Cardiovascular Prevention and Rehabilitation. Eur. J. Cardiovasc. Prev. Rehabilit. Off. J. Eur. Soc. Cardiol. Work. Groups Epidemiol. Prev. Cardiac Rehabilit. Exerc. Physiol. 2010, 17, 1-17. [CrossRef]

52. O'Gara, P.T.; Kushner, F.G.; Ascheim, D.D.; Casey, D.E., Jr.; Chung, M.K.; de Lemos, J.A.; Ettinger, S.M.; Fang, J.C.; Fesmire, F.M.; Franklin, B.A.; et al. 2013 ACCF/AHA guideline for the management of ST-elevation myocardial infarction: Executive summary: A report of the American College of Cardiology Foundation/American Heart Association Task Force on Practice Guidelines: Developed in collaboration with the American College of Emergency Physicians and Society for Cardiovascular Angiography and Interventions. Catheter. Cardiovasc. Interv. Off. J. Soc. Card. Angiogr. Interv. 2013, 82, E1-E27. [CrossRef]

53. Gibbons, R.J.; Balady, G.J.; Bricker, J.T.; Chaitman, B.R.; Fletcher, G.F.; Froelicher, V.F.; Mark, D.B.; McCallister, B.D.; Mooss, A.N.; O'Reilly, M.G.; et al. ACC/AHA 2002 guideline update for exercise testing: Summary article. A report of the American College of Cardiology/American Heart Association Task Force on Practice Guidelines (Committee to Update the 1997 Exercise Testing Guidelines). J. Am. Coll. Cardiol. 2002, 40, 1531-1540. [CrossRef]

54. Ware, J.E., Jr.; Sherbourne, C.D. The MOS 36-item short-form health survey (SF-36). I. Conceptual framework and item selection. Med. Care 1992, 30, 473-483. [CrossRef] 
55. Zigmond, A.S.; Snaith, R.P. The hospital anxiety and depression scale. Acta Psychiatr. Scand. 1983, 67, 361-370. [CrossRef] [PubMed]

56. Spielberger, C.D.G.R.; Lushene, R.; Vagg, P.R.; Jacobs, G.A. Manual for the State-Trait Anxiety Inventory; Consulting Psychologists Press: Palo Alto, CA, USA, 1983.

57. Bunevicius, A.; Staniute, M.; Brozaitiene, J.; Pop, V.J.; Neverauskas, J.; Bunevicius, R. Screening for anxiety disorders in patients with coronary artery disease. Health Qual. Life Outcomes 2013, 11, 37. [CrossRef] [PubMed]

58. Staniute, M.; Brozaitiene, J. Changes in health-related quality of life among patients with coronary artery disease: A 2-year follow-up. Medicina 2010, 46, 843-850. [CrossRef] [PubMed]

59. Bunevicius, A. Reliability and validity of the SF-36 health survey questionnaire in patients with brain tumors: A cross-sectional study. Health Qual. Life Outcomes 2017, 15, 92. [CrossRef] [PubMed]

60. Kazukauskiene, N.; Burkauskas, J. Mental distress factors and exercise capacity in patients with coronary artery disease attending cardiac rehabilitation program. Int. J. Behav. Med. 2018, 25, 38-48. [CrossRef]

61. Denollet, J.; Pedersen, S.S.; Daemen, J.; de Jaegere, P.; Serruys, P.W.; van Domburg, R.T. Reduced positive affect (anhedonia) predicts major clinical events following implantation of coronary-artery stents. J. Intern. Med. 2008, 263, 203-211. [CrossRef]

62. Bunevicius, A.; Peceliuniene, J.; Mickuviene, N.; Valius, L.; Bunevicius, R. Screening for depression and anxiety disorders in primary care patients. Depress. Anxiety 2007, 24, 455-460. [CrossRef] [PubMed]

63. Burkauskas, J.; Brozaitiene, J.; Bunevicius, A.; Neverauskas, J.; Zaliunaite, V.; Bunevicius, R. Association of depression, anxiety, and type $d$ personality with cognitive function in patients with coronary artery disease. Cognit. Behav. Neurol. Off. J. Soc. Behav. Cognit. Neurol. 2016, 29, 91-99. [CrossRef] [PubMed]

64. Bunevicius, R.; Matulevicius, V. Short-lasting behavioural effects of thyrotropin-releasing hormone in depressed women: Results of placebo-controlled study. Psychoneuroendocrinology 1993, 18, 445-449. [CrossRef]

65. Buneviciute, J.; Staniute, M.; Brozaitiene, J.; Girdler, S.S.; Bunevicius, R. Mood symptoms and personality dimensions as determinants of health-related quality of life in patients with coronary artery disease. J. Health Psychol. 2013, 18, 1493-1504. [CrossRef]

66. Comrey, A.; Lee, H. Interpretation and application of factor analytic results. Comrey AL Lee HB First Course Factor Anal. 1992, 2, 1992.

67. MacCallum, R.C.; Widaman, K.F.; Zhang, S.; Hong, S. Sample size in factor analysis. Psychol. Methods 1999, 4, 84. [CrossRef]

68. Terwee, C.B.; Bot, S.D.; de Boer, M.R.; van der Windt, D.A.; Knol, D.L.; Dekker, J.; Bouter, L.M.; de Vet, H.C. Quality criteria were proposed for measurement properties of health status questionnaires. J. Clin. Epidemiol. 2007, 60, 34-42. [CrossRef]

69. Taber, K.S. The use of Cronbach's alpha when developing and reporting research instruments in science education. Res. Sci. Educ. 2018, 48, 1273-1296. [CrossRef]

70. Briggs, S.R.; Cheek, J.M. The role of factor analysis in the development and evaluation of personality scales. J. Personal. 1986, 54, 106-148. [CrossRef]

71. Gentile, S.; Delaroziere, J.; Favre, F.; Sambuc, R.; San Marco, J. Validation of the French 'multidimensional fatigue inventory'(MFI 20). Eur. J. Cancer Care 2003, 12, 58-64. [CrossRef]

72. Smets, E.; Garssen, B.; Cull, A.; de Haes, J. Application of the multidimensional fatigue inventory (MFI-20) in cancer patients receiving radiotherapy. Brit. J. Cancer 1996, 73, 241. [CrossRef] [PubMed]

73. Smedegaard, L.; Numé, A.K.; Charlot, M.; Kragholm, K.; Gislason, G.; Hansen, P.R. Return to work and risk of subsequent detachment from employment after myocardial infarction: Insights from Danish Nationwide Registries. J. Am. Heart Assoc. 2017, 6. [CrossRef] [PubMed]

74. Reibis, R.; Salzwedel, A.; Abreu, A.; Corra, U.; Davos, C.; Doehner, W.; Doherty, P.; Frederix, I.; Hansen, D.; Christine Iliou, M.; et al. The importance of return to work: How to achieve optimal reintegration in ACS patients. Eur. J. Prev. Cardiol. 2019, 26, 1358-1369. [CrossRef]

Publisher's Note: MDPI stays neutral with regard to jurisdictional claims in published maps and institutional affiliations. 